\title{
A Comparative Study of Three Percutaneous Pinning Techniques for Paediatric Supracondylar Humeral Fractures
}

\author{
Mohamed Othman*, Ahmed Nahla, Ahmed El-Malt \\ Department of Orthopedics, Faculty of Medicine, Zagazig University, Egypt
}

*Corresponding Author: Mohamed Othman, Department of Orthopedics, Faculty of Medicine, Zagazig University, Egypt.E-mail: yousufmmkh@gmail.com

\begin{abstract}
Background: The currently accepted treatment for displaced supracondylar humeral fractures in children is closed reduction and percutaneous pinning. However, controversy exists about the optimal $K$-wire configuration required to provide and maintain adequate fracture stability while minimizing the risk of nerve injury. The aim of this study was to evaluate three different pinning techniques for paediatric supracondylar humeral fractures.
\end{abstract}

Patients and Methods: Forty seven children with Gartland's types II $(n=22)$ and III (n=25) supracondylar humeral fractures were treated at our institution by closed reduction and percutaneous pinning, between 2013 and 2015. The mean age of patients was 5.5+2.8 years (range: 1.7-10 yrs.). They were randomised to three different methods of pinning: either with medial-lateral crossed pins $(n=17)$, with lateral crossed pins ( $n=14$ ) or with two-three lateral parallel or divergent pins $(n=16)$ respectively.

Results: Two cases were lost to follow-up. The mean follow-up period of the remaining 45 patients was $7 \pm 1.5$ months (range; 6-10 months). According to criteria of Flynn et al., clinical cosmetic outcome was satisfactory in $93.75 \%, 92.86 \%$ and $93.34 \%$ respectively. The functional outcome was satisfactory in $87.5 \%, 92.86 \%$ and 93.34\% respectively. The differences were not statistically-significant. Radiologically, there was no difference with regard to maintenance of fracture reduction in either plane. Iatrogenic postoperative ulnar nerve injuries occurred in two cases of medial-lateral pinning group (12.5\%) but none after the lateral pinning techniques. All cases recovered completely on observation within a mean of $3 \pm 1.1$ months (range; 3 weeks -5 months).

Conclusions: All the three methods are effective in achieving fracture stability and the maintenance of reduction. Lateral-pins are safer for the ulnar nerve than medial-pins. Lateral parallel or divergent pinning is easier and has a lesser rate of pin tract infection than lateral crossed pins. Therefore, only lateral two - three parallel or divergent pins fixation is our preferred method for fixation of displaced or angled supracondylar humeral fractures in children.

Keywords: Supracondylar humeral fractures in children, closed reduction, Medial-lateral crossed-pin fixation. Lateral crossed pinning. Lateral parallel or divergent pins.

\section{INTRODUCTION}

Supracondylar fracture is one of the most common elbow injuries in children (1). Currently, closed reduction and percutaneous pinning of Gartland's types II and III supracondylar fractures of the humerus in children have become the standard method of treatment $(2,3)$. However, controversy exists about the optimal K-wires configuration required to provide adequate fracture stability to maintain reduction and promote proper union while minimizing the risk of nerve injury $(3,4)$. Biomechanical studies have shown increased rotational stability for crossed-pin fixation but significant rates of ulnar nerve injury have been reported (4-6). To achieve fracture stability and avoid ulnar nerve injury, many options have been mentioned in the literature; including medial - lateral crossed pins, lateral crossed pins (Dorgan's technique) and lateral parallel or divergent pins $(2,7)$.

The aim of this study was to evaluate three different pinning configurations used in the treatment of Gartland's types II and III supracondylar humeral fractures in children, mainly regarding maintenance of fracture reduction and avoidance of complications. 


\section{Patients And Methods}

Forty seven children with Gartland's types II $(n=22)$ and III $(n=25)$ supracondylar humeral fractures were treated at our institution by closed reduction and percutaneous pinning, between 2013 and 2015. The mean age of the patients was $5.5 \pm 2.8$ years (range; $1.7-10$ yrs.). The exclusion criteria were flexion-type fractures, open fractures, fractures that required open reduction, vascular injuries (that required vascular surgery) found on presentation, previous ipsilateral elbow fracture, those presenting after three days of injury and loss from follow-up. The study was approved by Institutional Ethical Committee and a written consent to participate in the study after explanation of risks and benefits, was taken. The surgery was done within the first day after presentation. The patients were randomised to three different methods of pinning: either with medial-lateral crossed pins $(\mathrm{n}=17)$, with lateral crossed pins [Dorgan's technique] $(n=14)$ or with two - three lateral parallel or divergent pins [lateral non-crossed pins] $(n=16)$. Preoperative assessment included history taking, clinical and radiological examination of both elbows.

\subsection{Operative Technique}

Closed reduction was performed under general anaesthesia after complete sterilization and drapping in supine position, without tourniquet, under fluoroscopy. Once a satisfactory reduction had been obtained (8), closed pinning of the fracture was done by one of 3 techniques:

a. Medial-lateral crossed pinning: This was achieved by retrograde passing two crossed $\mathrm{K}$-wires from both the medial and the lateral epicondyles. The lateral pin was inserted first so that the medial pin can be placed with the elbow in less flexion to avoid ulnar nerve injury. For medial pin insertion, the ulnar nerve was palpated and pushed posteriorly with the thumb. The pins must cross above and not at the fracture line (1).

b. Dorgan's lateral crossed pinning: The first wire was introduced through the lateral condyle in a retrograde direction (ascending) across the fracture and into the medial cortex. The second wire was introduced through the lateral cortex, proximal to the fracture line and driven in an antegrade direction (descending) across the fracture line into the medial condyle. The medial condyle should not be penetrated. The wires must cross above the fracture line. Occasionally, the second wire may skid down the lateral cortex during introduction. To avoid this, the wire was directed perpendicular to the cortex until the cortex was penetrated, pulled back, and then redirected towards the medial condyle (7).

c. Lateral parallel or divergent pinning: One pin was placed into the distal fragment, beginning laterally, directed obliquely toward the medial column, and then driven across the olecranon fossa, fracture site, and through the medial cortex of the distal humeral metaphysis proximal to the fracture site. This pin is expected to have the same effect as a medial entry pin. The first pin was inserted routinely across the olecranon fossa. The second pin is positioned up the lateral column in a direction divergent or parallel to the first, which maximizes pin separation at the fracture site. This is the key point of this procedure. Dynamic testing is necessary under fluoroscopy. If there is still significant motion, a third pin is inserted between the first and second pins (2).

- Using fluoroscopy, fracture stability was tested. The wires were then bent, cut and left outside the skin, facilitating their removal. The pulse and capillary perfusion of the hand were evaluated after reduction, after fixation and then postoperatively. All the elbows were immobilized using a well padded posterior above elbow slab with elbow flexed to $60-90^{\circ}$ as tolerated.

- The pin size was selected according to the age of the child and the size of the arm $(1.6 \mathrm{~mm}$ for younger children and 1.8-2.0 mm for older children).

\subsection{Postoperative Care and Follow-Up}

Immediate postoperative neurovascular assessment was performed. AP and lateral radiographs were performed to assess fracture reduction. The children were discharged home when comfortable (usually after 1-2 days) and were seen in the clinic one week after surgery for clinical and radiographic examination. If these were acceptable, the child was seen again after four weeks for removal of back slab and the K-wires after radiographic confirmation of a reasonable radiological union, in the outpatient clinic. A collar-and-cuff sling was then placed for a further two weeks. Six weeks postoperatively, the sling was discarded and physiotherapy commenced. After that, patients 
were followed-up each two weeks in the next six weeks then monthly till restoration of full ROM.

\subsection{Methods of Assessment}

- Clinical assessment: by Flynn et al's criteria (9) [Table.1] and neurologic examination.

- Radiologic assessment of maintenance of reduction :

a. In the coronal plane by Baumann's angle; measured immediately postoperative; at the final follow up and the difference in between. A change in Baumann's angle of $>$ $12^{\circ}$ was defined as a major loss of reduction; a change from $6^{\circ}$ to $12^{\circ}$ as a mild displacement; and a change of $<6^{\circ}$ as no displacement (10).

b. In the sagittal plane by lateral humeral shaft-capitellar angle; measured immediately postoperative; at the final follow up and the difference in between (2).

Table1: The Cosmetic and Functional Criteria of Flynn Et Al. (9)

\begin{tabular}{|c|c|c|}
\hline Rating & $\begin{array}{c}\text { Cosmetic factor } \\
\text { (Carrying angle } \\
\text { loss) }\end{array}$ & $\begin{array}{c}\text { Functional factor } \\
\text { (loss of motion) }\end{array}$ \\
\hline Excellent & $0-5^{\circ}$ & $0-5^{\circ}$ \\
\hline Good & $6-10^{\circ}$ & $6-10^{\circ}$ \\
\hline Fair & $11-15^{\circ}$ & $11-15^{\circ}$ \\
\hline Poor & $>15^{\circ}$ & $>15^{\circ}$ \\
\hline
\end{tabular}

\subsection{Statistical Analysis}

Achieved data were analyzed using Microsoft Excel software. Data were then imported into Statistical Package for the Social Sciences (SPSS version 20.0) software for analysis. The data were expressed as number and percentage, with mean \pm SD. The following tests were used to test differences for significance; difference and association of qualitative variable by Chi square test $\left(\mathrm{X}^{2}\right)$ or Fisher Exact. Differences between parametric multiple quantitative independent groups by ANOVA test, paired by paired t test. $\mathrm{P}$ value was set at $<0.05$ for significant results $\&<0.001$ for high significant result. (11)

\section{RESUltS}

Two cases were lost to follow-up. The mean follow-up period of the remaining 45 patients was $7 \pm 1.5$ months (range: 6-10 months).

\subsection{Clinical Outcome}

According to Flynn et al.'s criteria (9), the cosmetic outcome was satisfactory in $93.75 \%$ and fair in $6.25 \%$ in medial-lateral pinning group and satisfactory in $92.86 \%$ and fair in $7.14 \%$ in lateral crossed pinning group, while it was satisfactory in $93.34 \%$ and fair in $6.67 \%$ in lateral non-crossed pinning group. Statistical analysis showed no significant difference

Table2: Cosmetic Outcome (Carrying Angle Loss)

\begin{tabular}{|c|c|c|c|c|c|}
\hline Rating & $\begin{array}{c}\text { Medial-Lateral Crossed } \\
\text { Pins }(\mathbf{N = 1 6 )}\end{array}$ & $\begin{array}{c}\text { Lateral Crossed Pins } \\
(\mathbf{N = 1 4 )}\end{array}$ & $\begin{array}{c}\text { Lateral Non-Crossed } \\
\text { Pins (N=15) }\end{array}$ & $\begin{array}{c}\text { P- } \\
\text { Value }\end{array}$ & P \\
\hline Excellent & $7(43.75 \%)$ & $6(42.86 \%)$ & $7(46.67 \%)$ & 0.9 & \\
\hline Good & $8(50 \%)$ & $7(50 \%)$ & $7(46.67 \%)$ & 0.89 \\
\hline Fair & $1(6.25 \%)$ & $1(7.14 \%)$ & $1(6.67 \%)$ & 0.97 & 0.99 \\
\hline Poor & 0 & 0 & 0 & ---- & \\
\hline
\end{tabular}

The functional outcome was satisfactory in $87.5 \%$ and unsatisfactory in $12.5 \%$ in mediallateral pinning group and satisfactory in 92.86 $\%$ and fair in $7.14 \%$ in lateral crossed pinning

Table 3: Functional outcome (loss of motion) group, while it was satisfactory in $93.34 \%$ and fair in $6.67 \%$ in lateral noncrossed pinning group. Statistical analysis showed no significant difference (table 3).

\begin{tabular}{|c|c|c|c|c|c|}
\hline Rating & $\begin{array}{c}\text { Medial-lateral crossed } \\
\text { pins }(\mathbf{n = 1 6})\end{array}$ & $\begin{array}{c}\text { Lateral crossed pins } \\
(\mathbf{n = 1 4})\end{array}$ & $\begin{array}{c}\text { Lateral non-crossed } \\
\text { pins }(\mathbf{n = 1 5})\end{array}$ & P-value & P \\
\hline Excellent & $7(43.75 \%)$ & $5(35.71 \%)$ & $6(40 \%)$ & 0.66 & \\
\hline Good & $7(43.75 \%)$ & $8(57.14 \%)$ & $8(53.33 \%)$ & 0.36 \\
\hline Fair & $1(6.25 \%)$ & $1(7.14 \%)$ & $1(6.67 \%)$ & 0.67 & 0.89 \\
\hline Poor & $1(6.25 \%)$ & 0 & 0 & 0.36 & \\
\hline
\end{tabular}

\subsection{Radiologic Outcome}

-The fractures united at a mean of $4 \pm 1.2$ weeks (range: 3-6 weeks).
- Assessment of maintenance of reduction:

a. In the coronal plane: The mean Baumann's angle in the three groups (medial-lateral 
pinning group, lateral crossed pinning group and lateral non crossed pinning group); immediately postoperative was; $17.4^{\circ} \pm 0.5$, $17.1^{\circ} \pm 0.5$ and $17.4^{\circ} \pm 0.55$ respectively and at the final follow up was $17.3^{\circ} \pm 0.4$, $16.9^{\circ} \pm 0.6$ and $17.2^{\circ} \pm 0.49$ respectively, with a mean difference of $0.11^{\circ} \pm 0.07,0.15^{\circ} \pm 0.08$

Table 4: Baumann's angle loss and $\quad 0.17^{\circ} \pm 0.09$ respectively. Statistical analysis showed no significant difference (Table 4). According to the criteria outlined by Kocher et al. (10), no patient had a loss of reduction (either mild or major) as the change in Baumann's angle was $<6^{\circ}$ in all patients.

\begin{tabular}{|c|c|c|c|c|}
\hline Mean Baumann's angle & $\begin{array}{c}\text { Medial-lateral } \\
\text { crossed pins }\end{array}$ & $\begin{array}{c}\text { Lateral crossed } \\
\text { pins }\end{array}$ & Lateral non-crossed pins & P-value \\
\hline Immediate postoperative & $17.4^{\mathbf{0}} \pm 0.5$ & $17.1^{\mathbf{0}} \pm 0.5$ & $17.4^{\circ} \pm 0.55$ & 0.16 \\
\hline At final followup & $17.3^{\mathbf{0}} \pm 0.4$ & $16.9^{\mathbf{0}} \pm 0.6$ & $17.2^{\circ} \pm 0.49$ & 0.14 \\
\hline $\begin{array}{c}\text { Difference bet. Immediate } \\
\text { \& final angle }\end{array}$ & $0.11^{\circ} \pm 0.07$ & $0.15^{\circ} \pm 0.08$ & $0.17^{\circ} \pm 0.09$ & 0.14 \\
\hline $\mathrm{P}$ & 0.42 & 0.28 & 0.282 & \\
\hline
\end{tabular}

b. In the sagittal plane: The mean lateral humeral shaft-capitellar angle in the three groups ( medial-lateral pinning group, lateral crossed pinning group and lateral noncrossed pinning group); immediately postoperative was; $38.4^{\circ} \pm 1.4, \quad 37.6^{\circ} \pm 1.2$ and $37.5^{\circ} \pm 1.3$ respectively and at the final followup was $38.1^{\circ} \pm 1.2, \quad 37.2^{\circ} \pm 1.4 \quad$ and $37.2^{\circ} \pm 1.11$ respectively, with a mean difference of $0.3^{\circ} \pm 0.1, \quad 0.38^{\circ} \pm 0.12$ and $0.31^{\circ} \pm 0.1$ respectively. Statistical analysis showed no significant difference (Table 5).

Table 5: Lateral humeral shaft-capitellar angle loss

\begin{tabular}{|c|c|c|c|c|}
\hline $\begin{array}{c}\text { Mean Lateral Humeral } \\
\text { Shaft- Capitellar Angle }\end{array}$ & $\begin{array}{c}\text { Medial-Lateral } \\
\text { Crossed Pins }\end{array}$ & $\begin{array}{c}\text { Lateral Crossed } \\
\text { Pins }\end{array}$ & $\begin{array}{c}\text { Lateral Non- } \\
\text { Crossed Pins }\end{array}$ & $\begin{array}{c}\text { P- } \\
\text { Value }\end{array}$ \\
\hline Immediate postoperative & $38.4^{\mathbf{0}} \pm 1.4$ & $37.6^{\mathbf{0}} \pm 1.2$ & $37.5^{\mathbf{0}} \pm 1.3$ & 0.11 \\
\hline At final followup & $38.1^{\mathbf{0}} \pm 1.2$ & $37.2^{\mathbf{0}} \pm 1.4$ & $37.2^{\mathbf{0}} \pm 1.11$ & 0.12 \\
\hline $\begin{array}{c}\text { Difference bet. Immediate } \\
\text { \& final angle }\end{array}$ & $0.3^{\mathbf{o}^{\mathbf{0}} \pm 0.1}$ & $0.38^{\mathbf{0}} \pm 0.12$ & $0.31^{\mathbf{0}} \pm 0.1$ & 0.13 \\
\hline $\mathrm{P}$ & 0.24 & 0.19 & 0.29 & \\
\hline
\end{tabular}

\subsection{Complications and Problems}

(a) Associated nerve injuries (table 6): Preoperative nerve injuries were present in three cases $(6.67 \%)$; radial nerve in one and anterior interosseous nerve in two. Iatrogenic postoperative ulnar nerve injuries occurred in two cases $(4.44 \%)$; both in medial-lateral pinning group $(12.5 \%)$ but none in lateral crossed pinning group or lateral noncrossed pinning group. The difference was found to be statisticallysignificant $(\mathrm{P}$-value $=0.00002)$. All cases recovered completely on conservative management within a mean of $3 \pm 1.1$ months (range: 3 weeks -5 months).

(b) Pin tract infection: occurred in two cases $(12.5 \%)$ in medial-lateral pins group, in one case $(6.67 \%)$ in lateral noncorossed pins group and in three cases (21.4\%) in lateral crossed pins goup ( most in proximal pin). All resolved completely with local wound care and nothing required early pin removal.

(c) No iatrogenic vascular injuries

Table 6: Associated nerve injuries

\begin{tabular}{|c|c|c|c|c|c|}
\hline Nerve injury & $\begin{array}{c}\text { Medial-lateral crossed } \\
\text { pins }(\mathbf{n = 1 6})\end{array}$ & $\begin{array}{c}\text { Lateral crossed } \\
\text { pins }(\mathbf{n = 1 4})\end{array}$ & $\begin{array}{c}\text { Lateral non-crossed } \\
\text { pins }(\mathbf{n = 1 5})\end{array}$ & $\begin{array}{c}\text { Total } \\
(\mathbf{n}=\mathbf{4 5})\end{array}$ & P-value \\
\hline preoperative & $1(\mathrm{radial})$ & $1(\mathrm{AION})$ & $1(\mathrm{AION})$ & $3\{6.67 \%)$ & ------ \\
\hline $\begin{array}{c}\text { Iatrogenic } \\
\text { postoperative }\end{array}$ & $2(12.5 \%)(\mathrm{ulnar})$ & 0 & 0 & $2(4.44 \%)$ & $\begin{array}{c}0.00002 \\
* *\end{array}$ \\
\hline
\end{tabular}

AION = Anterior Interosseous Nerve.

\section{DISCUSSION}

Supracondylar fracture is one of the most common elbow injuries in children (1). While closed reduction and percutaneous K-wires stabilization is the currently-accepted treatment of displaced supracondylar fractures of the 
humerus in children, there is still argument on the optimal configuration of those K- wires, as regards fracture stability and ulnar nerve safety $(1,2,4)$.

In our series, comparing three groups of medial-lateral pinning, Dorgan's technique and lateral noncrossed pinning respectively using Flynn et al's score (9), the clinical cosmetic outcome was satisfactory in $93.75 \%, 92.86 \%$ and $93.34 \%$ respectively. The functional outcome was satisfactory in $87.5 \%, 92.86 \%$ and 93.34\% respectively. The differences were not statistically-significant. Radiologically, there was no difference with regard to maintenance of fracture reduction in either plane.

Our results compare favorably with others. In the series of Foead et al., (12), comparing two groups of medial-lateral pinning and lateral noncrossed pinning, cosmetically, the outcome was satisfactory in $89.28 \%$ and $88.89 \%$ respectively. Functionally, it was satisfactory in $75 \%$ and $81.48 \%$ respectively. Both cosmetic and functional differences were statistically insignificant. In the study of Sahu (13), comparing medial-lateral crossed pins and lateral non-crossed pins, no much difference between both methods in terms of stability was found. Sudheendra and Nazareth (14) excuted a comparative study of outcome of percutaneous lateral and crossed pinning in 45 children with type III supracondylar fractures. The overall cosmetic and functional outcome was satisfactory in all cases. The differences between the two groups were statistically insignificant. Lee et al., (2) used only 3 lateral divergent or parallel Kirschner wires to treat 24 type II, and 37 type III fractures. An excellent clinical result was achieved in $91.8 \%$ and a good result was achieved in $8.2 \%$ of cases. Radiologically, there was no loss of reduction of any fracture. In the series of Eberhardt et al (15) using Dorgan's lateral crossed wiring, excellent to good functional results were achieved in 93\%. Their cosmetic results were 93\% excellent and $7 \%$ good results with no poor result. Radiologically, $87 \%$ of their cases had normal humeral shaft- condylar angle. There was no case of secondary displacement.

By contrast, Zamzam and Bakarman (16), compared crossed versus lateral non-crossed pinning in 41 type II and 67 type III fractures. Type III fractures fixed by two lateral pins were found significantly prone to postoperative instability, late complications and need for medial pin fixation.

\section{Discussion of the stability of the construct and maintenance of reduction includes biomechanical studies and clinical data.}

Biomechanical study of Zionts etal. (5) meas ured the resistance to rotation of the distal fragment of simulated supracondylar fractures fixed with four different pin configurations. They found that the crossed-wire configuration, placed from the medial and lateral condyles, was the most stable arrangement. They promoted the use of the crossed-pin configuration but mentioned that with significant swelling, the two lateral parallel pins could be considered an inferior but acceptable option. More recently, Lee et al. (6) using a saw-bone model, found that two divergent lateral pins were comparable to cross-wires in extension, varus and valgus loading but were inferior in axial rotation testing. While Dorgan's technique does not include supporting biomechanical data, the crossed-wire configuration obtained by inserting both wires from the lateral side is similar to that obtained via the traditional medial and lateral technique $(7,17)$. Stability of lateral parallel or divergent pinning is maximized (if perfectly done); by maximizing pin separation at the fracture site ( this is the key point of this procedure ) and adding a third pin in between (if there is still significant motion), thus stabilizing all three columns. Furthermore, insertion across the olecranon fossa adds two more cortices of fixation (2).

According to the clinical data in our series and that of others, the use of two-three parallel or divergent lateral pins provides adequate stability, with no loss of reduction and with minimal or no risk of ulnar nerve injury, and is therefore gaining in popularity $(2,18-20)$.

Concerning iatrogenic ulnar nerve injury, in our study, two cases $(4.44 \%)$ occurred; both after medial-lateral crossed pinning $(12.5 \%)$ but nothing after Dorgan's technique or lateral noncrossed pins. This difference was statistically significant. All cases recovered completely within three months.

Skaggs et al.(4) reported 17 ulnar nerve injuries in 220 of their patients $(7.7 \%)$ with crossed pins but nothing in 125 of their patients with only lateral pins. Shannon et al. (7), Lee et al.(2) and 
Sudheendra and Nazareth (14) did not report any case of ulnar nerve injury after lateral pinning. However, Foead et al.(12) reported two cases of ulnar nerve deficit when fracture fixation was performed by two lateral pin fixation and suggested that manipulation was the cause. These data indicate that lateral-pins ( either crossed or parallel/divergent) decrease the rate of ulnar nerve injury when compared with medial-pins.

The incidence of reported iatrogenic ulnar nerve lesions with a medial pin ranges from $1.4 \%$ to $15.6 \%(16,21-23)$.

Different techniques are performed to decrease the rate of ulnar nerve injury associated with the medial pin; (a) the lateral pin is inserted first to allow elbow extension to less than $90^{\circ}$ position to allow ulnar nerve to be displaced posteriorly before inserting the medial pin. (b) the ulnar nerve is palpated and pushed posteriorly with thumb before inserting the medial pin (c) a small separate incision over the medial epicondyle to explore the ulnar nerve is required, if there is gross swelling $(8,16,22,24)$.

Iatrogenic nerve injuries could be due to (a) local irritation, pressure, kinking or penetration by a misdirected medial pin.(b) iatrogenic constriction of the cubital tunnel by an apparently correctly placed medial pin and damage of a hypermobile ulnar nerve that can subluxate anteriorly when the elbow is held in a hyperflexed position (c) complete transection of the nerve or neurotmesis was very uncommon. The prognosis was (a) benign in most cases and observation was the appropriate management; with full recovery within months (they were most likely neuropraxia or axonotmesis (Sunderland type 1 and 2) however, (b) permanent damage has been reported in the literature in a few cases,. Therefore, where the medial pin appears to have a position in the ulnar notch, it may be appropriate either to remove that pin and replace it with another in a more anterior position, or to perform early exploration $(2,16,21-23)$.

Although passing of pins across the olecranon fossa (in the lateral pining technique) has the advantage of a four cortical fixation (thus increasing the stability), it carries two theoretical risks; elbow stiffness and joint infection. Range of movement was satisfactory in our series and that of others $(2,10-14)$. Joint movement was not compromised because the pins were removed at approximately 4 weeks
(2). The only report of joint infection that we found was by Fowles and Kassab (25). The authors believed the infection to be related to the working environment rather than to operative technique $(16,25)$.

In Dorgan's technique, an important point was the possible difficulty of introduction and oblique direction of the proximal lateral pin. However, truely, this is not so difficult. The periosteum is typically thick in this age group, so even with an oblique approach the pin easily enters the cortex and can then be advanced toward the medial condyle as it traverses the fracture site. Occasionally, the proximal wire may skid down the lateral cortex during introduction. To avoid this, the wire was directed perpendicular to the cortex until the cortex was penetrated, pulled back, and then redirected towards the medial condyle (15).

Dorgan's technique has theoretical risks of injuring the radial and ulnar nerves by the proximal pin. The risk of radial nerve injury occurs at the site of the proximal wire entry. However, this pin does not appear to produce an increased risk to the radial nerve. There is a distance of $>2 \mathrm{~cm}$ between the radial nerve in this area on the lateral side and the pin introduction point, provided that the entry was metaphyseal or meta-diaphyseal and not higher in diaphysis. Also, at this level, the radial nerve is anterior to the lateral intermuscular septum. It can be avoided by entering the skin slightly posterior to the midcoronal plane. The proximal lateral pin can injure the ulnar nerve when drilling through the bony area of the medial condyle. The descending pin should not perforate the medial condyle to avoid ulnar nerve injury $(7,15)$.

We suggest that lateral parallel or divergent pinning has an advantage over Dorgan's technique considering the more difficulty of introduction and oblique direction of the proximal lateral pin and the higher rate of pin tract infection of the proximal pin of Dorgan's technique.

The principal strengths of this study were randomization of the patients for the pinning technique and regular clinical and radiographic evaluation. An important limitation in this study was the small number of cases in each group. A study involving larger numbers of patients with long-term follow-up is needed to clarify the differences between the different techniques. 


\section{FIGURES}

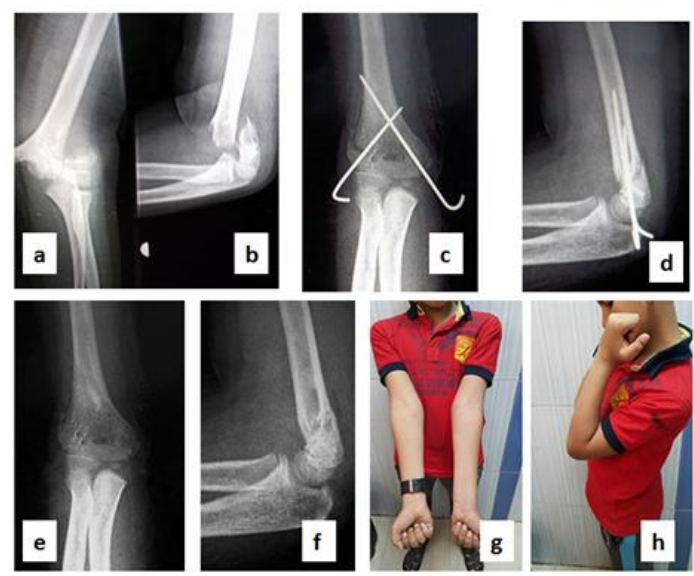

Figure1. Medical-Lateral Crossed Pins; $(a \& b)$; Preoperative, (c-f); Radiologic Outcome, ( $g \& h)$; Clinical Outcome
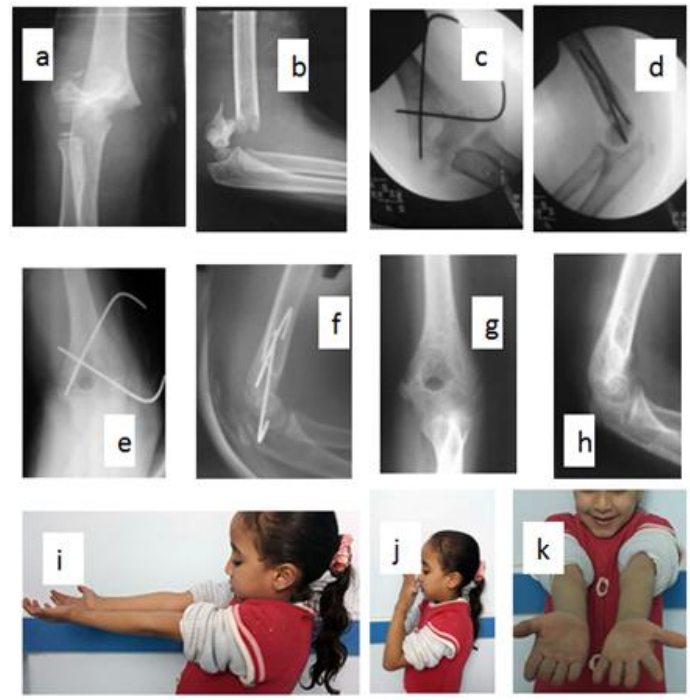

Figure2. Dorgan's Technique. (a\&b) Preoperative, (c-h) Radiologic Outcome, $(i-k)$ Clinical Outcome
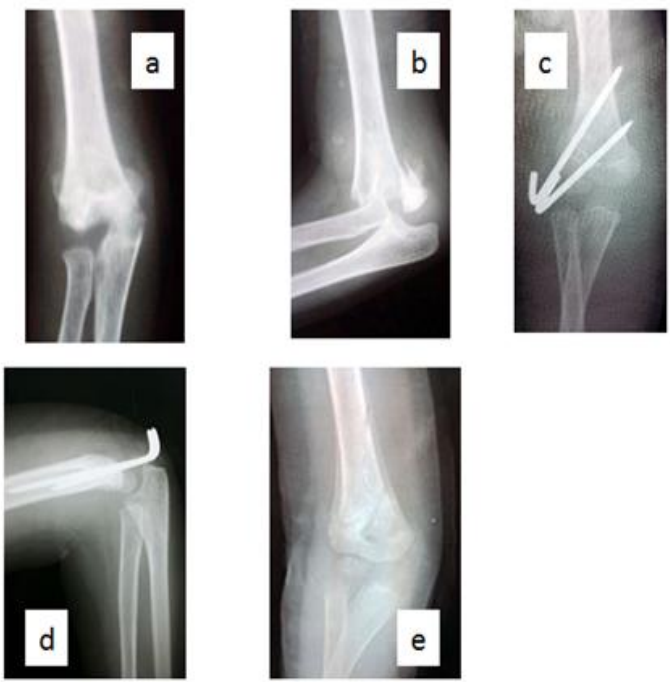

Figure3. Two Lateral Divergent Pins. (a\&b) Preoperative, (c-e); Radiologic Outcome
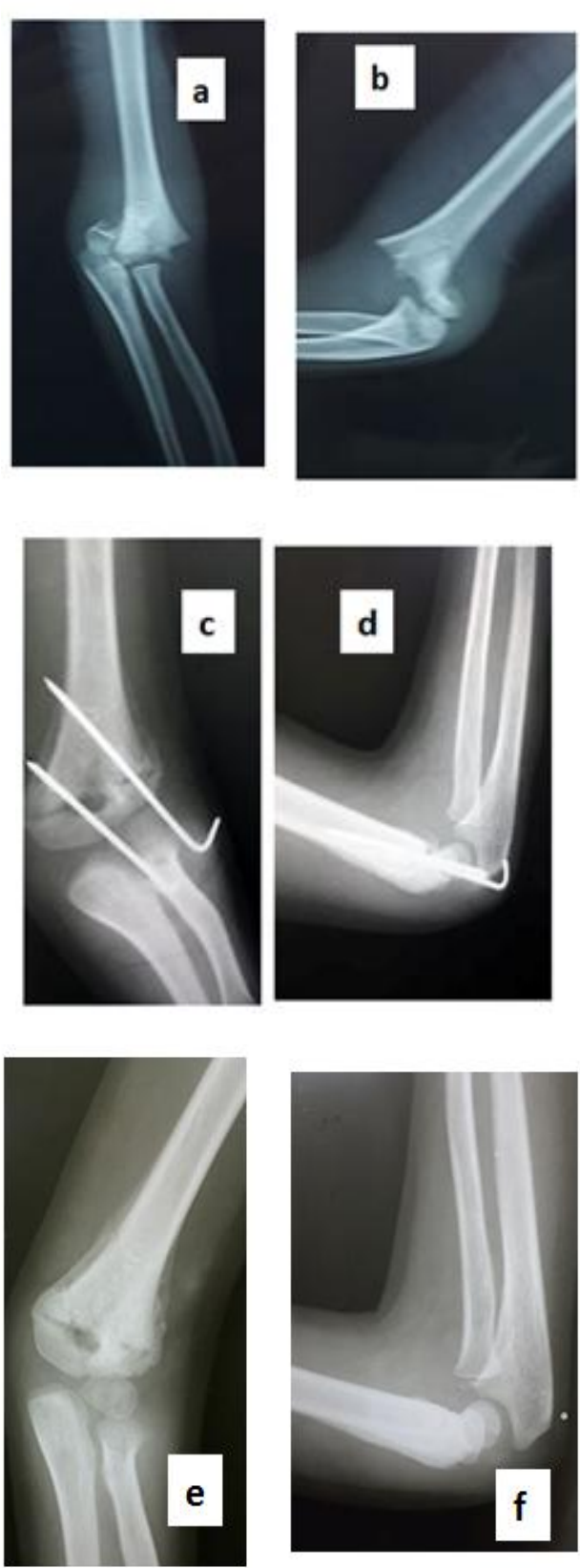

Figure4. Two Lateral Parallel Pins Fixation; $(a \& b)$ Preopereative, $(c \& d)$ After Pinning $(E \& F)$ After Pinning

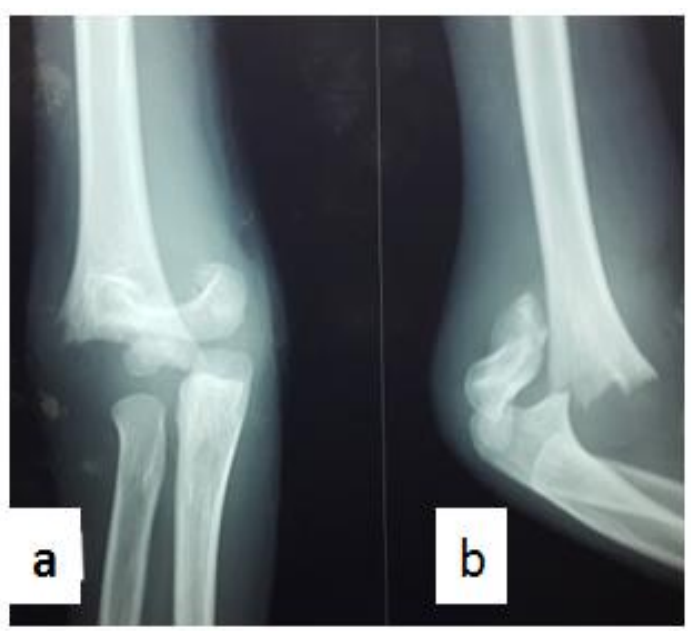



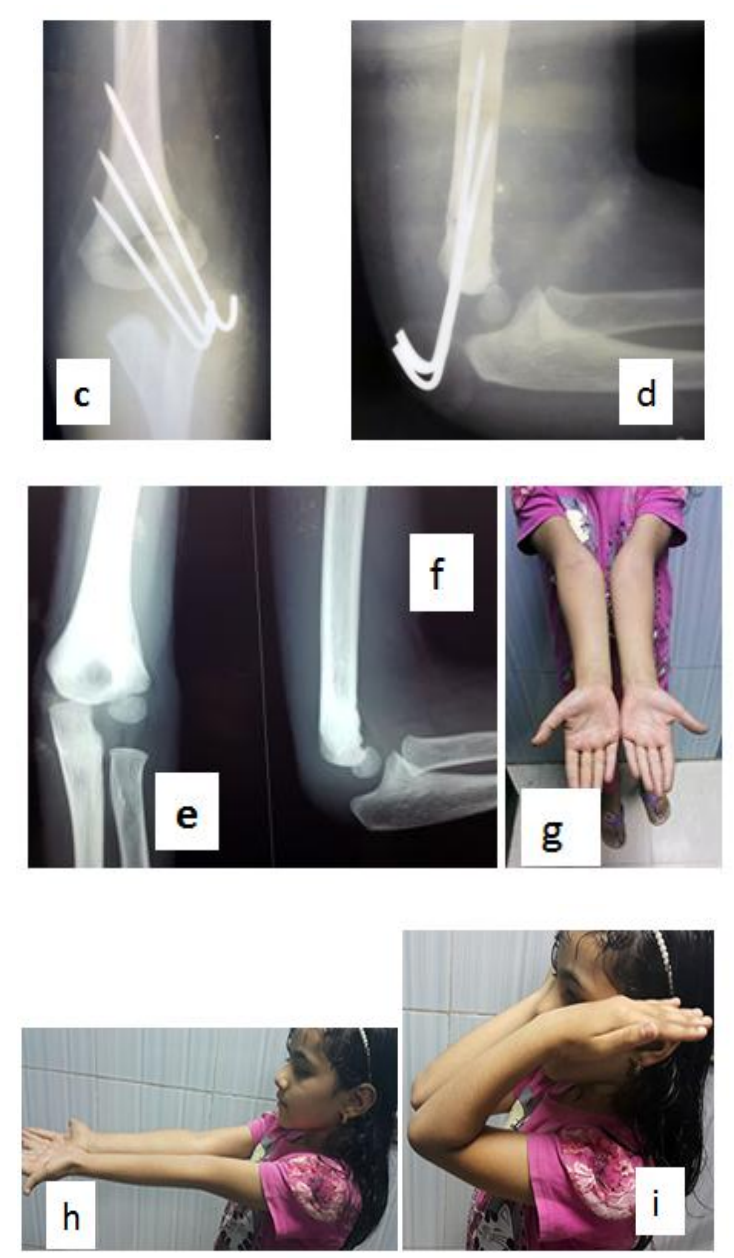

Figure5. (a\&b); Preoperative, (c-f) Radiologic Outcome, (g-i); Clinical Outcome

\section{CONCLusions}

As regards the fracture stability and the maintenance of reduction, all the three methods are comparable. As regards the ulnar nerve safety, lateral-pins (whether crossed or parallel/divergent) avoid or decrease the rate of ulnar nerve injury when compared with medialpins. Lateral parallel or divergent pinning is easier and has a lesser rate of pin tract infection than Dorgan's technique. Therefore, only lateral two - three parallel or divergent pins fixation is our preferred method for fixation of displaced or angled supracondylar humeral fractures in children; being effective for maintenance of reduction and safe for the ulnar nerve.

\section{REFERENCES}

[1] Singh S, Pai DR, Kaur A, Soe $\mathrm{HH}$ (2013) Crossed versus lateral pinning in the treatment of displaced extension-type supracondylar fractures of the humerus: a prospective study.the internet journal of orthopedic surgery. volume 21 number 2
[2] Lee YH, Lee SK, Kim BS, et al. (2008) Three lateral divergent or parallel pin fixations for the treatment of displaced supracondylar humerus fractures in children. J Pediatr Orthop;28:41722.

[3] Lee KM, Chung CY, Gwon DK, et al. (2012) Medial and lateral crossed pinning versus lateral pinning for supracondylar fractures of the humerus in children: decision analysis. $\mathbf{J}$ Pediatr Orthop. ; 32:131-8.

[4] Skaggs DL, Hale JM, Bassett J (2001) Operative treatment of supracondylar fractures of the humerus in children. The consequence of pin placement. J Bone Joint Surg Am; 83:735740

[5] Zionts LE, McKellop HA, Hathaway R (1994) Torsional strength of pin configurations used to fix supracondylar fractures of the humerus in children. J Bone Joint Surg Am;76:253Y256

[6] Lee SS, Mahar AT, Miesen D, et al.(2002) Displaced pediatric supracondylar humerus fractures: biomechanical analysis of percutaneous pinning techniques. J Pediatr Orthop.;22:440Y443.

[7] Shannon FJ, Mohan P, Chacko J, D'Souza LG (2004) Dorgan's percutaneous lateral cross wiring of supracondylar fractures of the humerus in children. J Pediatr Orthop.; 24:376379

[8] Mubarak SJ, Davids JR (1994) "Closed Reduction and percutaneous pinning of supracondylar fractures of the distal humerus in the child. In Morrey BF (ed.): MasterTechniques in Orthopaedic Surgery - Elbow." New York, Raven Press, 37

[9] Flynn JC, Matthews JG, Benoit RL (1974) Blind pinning of displaced supracondylar fractures of the humerus in children. Sixteen years experience with long-term follow up. J Bone Joint Surg Am ;56:263-72

[10] Kocher MS, Kasser JR, Waters PM, et al.( 2007) Lateral entry compared with medial and lateral entry pin fixation for completely displaced supracondylar humeral fractures in children. A randomized clinical trial. J Bone Joint Surg Am;89:706-12

[11] Bailey R A (2008) Design of Comparative Experiments. Cambridge University Press. ISBN 978-0-521-68357-9..

[12] Foead A, Penafort R, Saw A, Sengupta S (2004) Comparison of two methods of percutaneous pin fixation in displaced supracondylar fractures of the humerus in children. Malaysia Journal of Orthopaedic Surgery;12(1):76-82

[13] Sahu RL (2013) Percutaneous K-wire fixation in paediatric supracondylar fractures of 
humerus: A retrospective study. Niger Med J. Sep-Oct; 54(5): 329-334.

[14] Sudheendra PR, Nazareth EL(2014) A comparative study of outcome of percutaneous lateral and crossed pinning in the treatment of type III supracondylar fractures of humerus in children. Sch. J. App. Med. Sci.; 2(3A):959962 .

[15] Eberhardt O, Fernandez F, Ilchmann T, Parsch K (2007) Cross pinning of supracondylar fractures from a lateral approach. Stabilization achieved with safety: J Child Orthop; 1(2): 127-133

[16] Zamzam MM, Bakarman KA (2008) Treatment of displaced supracondylar humeral fractures among children: Crossed versus lateral pinning. Injury, 10.029

[17] Queally JM, Paramanathan N, Walsh JC, et al.(2010) Dorgan's lateral cross-wiring of supracondylar fractures of the humerus in children: A retrospective review: Injury; 41 : 568-571

[18] Topping RE, Blanco JS, Davis TJ (1995) Clinical evaluation of crossed-pin versus lateral pin fixation in displaced supracondylar humerus fractures. J Pediatr Orthop; 15:435-9.

[19] Skaggs DL, Cluck MW, Mostofi A, et al.( 2004) Lateral-entry pin fixation in the management of supracondylar fractures in children. J Bone Joint Surg Am; 86:702-7.
[20] Sibinski M, Sharma H, Sherlock DA (2006) Lateral versus crossed wire fixation for displaced extension supracondylar humeral fractures in children. Injury; 37:961-5.

[21] Lyons JP, Ashley E, Hoffer MM (1998) Ulnar nerve palsies after percutaneous cross-pinning of supracondylar fractures in children's elbows. J Pediatr Orthop; 18:43-5.

[22] Rasool MN (1998) Ulnar nerve injury after Kwire fixation of supracondylar humerus fractures in children. J Pediatr Orthop;18:68690.

[23] Kalenderer O, Reisoglu A, Surer L, Agus H (2008) how should one treat iatrogenic ulnar injury after closed reduction and percutaneous pinning of paediatric supracondylar humeral fractures? Injury; 39:463-6.

[24] Green DW, Widmann RF, Frank JS, Gardner MJ (2005) Low incidence of ulnar nerve injury with crossed pin placement for paediatric Supracondylar humerus fractures using a miniopen technique. J Orthop Trauma; 19:158-63.

[25] Fowles JV, Kassab MT (1974) Displaced supracondylar fractures of the elbow in children. A report on the fixation of extension and flexion fractures by two lateral percutaneous pins. J Bone Joint Surg Br;56:490-500

Citation: Mohamed Othman, Ahmed Nahla, Ahmed El-Malt, A Comparative Study of Three Percutaneous Pinning Techniques for Paediatric Supracondylar Humeral Fractures. ARC Journal of Orthopedics. 2017; 2(2):11-19. doi:dx.doi.org/ 10.20431/2456-0588.0202003.

Copyright: (c) 2017 Authors. This is an open-access article distributed under the terms of the Creative Commons Attribution License, which permits unrestricted use, distribution, and reproduction in any medium, provided the original author and source are credited. 